\title{
Intoxication with Over-the-Counter Antitussive Medication Containing Dihydrocodeine and Chlorpheniramine Causes Generalized Convulsion and Mixed Acidosis
}

\author{
Satoshi Murao ${ }^{1}$, Hiroaki Manabe ${ }^{2}$, Tetsuji Yamashita ${ }^{1}$ and Takashi Sekikawa ${ }^{1}$
}

\begin{abstract}
We report a 35-year-old man who was referred to our hospital with generalized convulsion and mixed acidosis presumably caused by abuse of SS-BRON ${ }^{\mathrm{TM}}$ tablets, an over-the-counter (OTC) antitussive medication sold in Japan. These tablets contain dihydrocodeine phosphate, methylephedrine, chlorpheniramine, and caffeine. Although it is difficult to discern which component caused these symptoms, it seems that dihydrocodeine phosphate or methylephedrine was involved in the addiction to SS-BRON ${ }^{\mathrm{TM}}$ and chlorpheniramine may have caused the generalized convulsion. It should be recognized that an OTC antitussive, which is quite easy to obtain, can be abused and subsequently induce serious intoxication.
\end{abstract}

Key words: antitussive, chlorpheniramine, codeine, convulsion, acidosis

(Inter Med 47: 1013-1015, 2008)

(DOI: 10.2169/internalmedicine.47.0925)

\section{Introduction}

Cases of intoxication with multiple drugs are frequently encountered in the emergency department. Assessment of the contribution of individual drugs in causing adverse events in these patients is complicated. Moreover, it is difficult to find information on overdoses or drug interactions with common over-the-counter (OTC) medications such as antitussives due to the paucity of cases reported. In this report, we describe a 35-year-old man who was referred to our hospital with generalized convulsion and mixed acidosis presumably caused by abuse of SS-BRON ${ }^{\mathrm{TM}}$ tablets, an OTC antitussive medication sold in Japan. These tablets contain dihydrocodeine phosphate, methylephedrine, chlorpheniramine, and caffeine.

\section{Case Report}

A 35-year-old man was referred to the emergency department of our hospital due to generalized convulsion. On arrival, his consciousness was confused and bilateral pupils were constricted to pinpoints. Systolic blood pressure was 143 $\mathrm{mmHg}$, diastolic blood pressure was $94 \mathrm{mmHg}$, heart rate was 113 beats per minute, and respiratory rate was 16 per minute. Laboratory results demonstrated normal complete blood cell count (white cell count was $9,000 / \mu 1$, red blood cell count was $474 \times 10^{4} / \mu \mathrm{l}$, hemoglobin was $14.8 \mathrm{~g} / \mathrm{dl}$, platelet count was $\left.45.2 \times 10^{4} / \mu \mathrm{l}\right)$, and blood sugar was $84 \mathrm{mg} / \mathrm{dl}$. Analysis of arterial blood gas demonstrated metabolic dominant mixed acidosis (pH 7.167, $\mathrm{PCO}_{2} 49.1$ Torr, $\mathrm{PO}_{2} 268.6$ Torr, $\mathrm{HCO}_{3} 17.4 \mathrm{mEq} / \mathrm{l}, \mathrm{BE}-11.3 \mathrm{mEq} / \mathrm{l}$, with 51 per minutes of oxygen inhalation) and lactate was elevated to 30.0 $\mathrm{mg} / \mathrm{dl}$. The results of liver function tests were normal. Creatine kinase was $455 \mathrm{IU} / \mathrm{l}$, blood urea nitrogen was $14 \mathrm{mg} /$ $\mathrm{dl}$, creatinine was $1.16 \mathrm{mg} / \mathrm{dl}$, uric acid was $9.9 \mathrm{mg} / \mathrm{dl}$, sodium was $144 \mathrm{mEq} / \mathrm{l}$, potassium was $4.2 \mathrm{mEq} / \mathrm{l}$, chloride was $103 \mathrm{mEq} / \mathrm{l}$, and C-reactive protein was below $0.1 \mathrm{mg} / \mathrm{dl}$. Fifteen minutes after arrival, he presented generalized convulsion. After the use of $20 \mathrm{mg}$ of diazepam, the convulsion was relieved and midazolam was continuously administered intravenously for sedation. Findings on magnetic resonance imaging of brain were normal. Twelve hours later, his consciousness recovered and he became almost alert; convulsion

${ }^{1}$ Department of Internal Medicine, Matsuyama Shimin Hospital, Matsuyama and ${ }^{2}$ Department of Neurosurgery, Matsuyama Shimin Hospital, Matsuyama

Received for publication January 16, 2008; Accepted for publication March 5, 2008

Correspondence to Dr. Satoshi Murao, smurao@matsuyama-shimin-hsp.or.jp 
did not recur. Electroencephalogram (EEG) findings recorded 24 hours after admission showed a suppressed $\alpha$ wave at the bilateral occipital region. Ten days after admission, EEG findings were normal.

The serum level of chlorpheniramine on admission was $0.43 \mathrm{mg} / \mathrm{l}$, although the therapeutic range is between 0.004 to $0.017 \mathrm{mg} / \mathrm{l}$. He had been taking SS-BRON ${ }^{\mathrm{TM}}$ tablets daily for more than five years. Although the recommended daily dose for adults of SS-BRON ${ }^{\mathrm{TM}}$ tablets is 12 tablets per day, he sometimes took more than 12 tablets a day. He had no previous history or family history of seizures or febrile convulsion. He had no history of abusing other drugs or alcohol.

\section{Discussion}

Most OTC antitussive drugs contain codeine, ephedrine, or dextromethorphan, which could cause psychological or physical dependence. Dependence and abuse of OTC antitussive have been known more than 20 years ago (1-4). In Japan, abuse of SS-BRON ${ }^{\mathrm{TM}}$ syrup, which contains dihydrocodeine phosphate, methylephedrine, chlorpheniramine, and caffeine, has been reported (1). As the abuse of SS$\mathrm{BRON}^{\mathrm{TM}}$ syrup prevailed, methylephedrine and dihydrocodeine were removed from its ingredients in 1989 (5). In the tablets, however, these constituents were not changed, i.e., commercially available SS-BRON ${ }^{\mathrm{TM}}$ tablets currently contain $30 \mathrm{mg}$ of dihydrocodeine phosphate, $50 \mathrm{mg}$ of methylephedrine, $8 \mathrm{mg}$ of chlorpheniramine, and $90 \mathrm{mg}$ of caffeine per twelve tablets, which is the daily usage dose for adults. Although the consequences of long-term abuse of SS-BRON ${ }^{\mathrm{TM}}$ have been reported to result in psychiatric symptoms (4), intoxication phenomena such as those in the present case are not well recognized. Recently, two cases of intoxication due to SS-BRON ${ }^{\mathrm{TM}}$ granules, of which contain the same ingredients as the tablet, have been reported $(6,7)$. Both of these cases presented with generalized convulsion and in one case, mixed acidosis was observed (7), which is similar to the present case.

Dihydrocodeine is an opioid, a morphine-like dependence-forming drug. The analgesic effect is less than one-tenth of that of morphine, but it has a potent antitussive effect (8). Although the potency of dependence is weak among opioids, continued usage in large doses can result in physical dependence. Pinpoint pupils observed in the present case indicated poisoning by dihydrocodeine. Methylephedrine is a sympathomimetic with a beta $a_{2}$ adrenergic stimulation effect. It also has a central stimulating effect and could cause psychological dependence. Caffeine has a central stimulating effect in large amounts and its participation of modulating dependency has been reported (9). The combined effect of these ingredients seems to form an addiction to this antitussive.

Chlorpheniramine is an antihistamine, often included in antitussives although the effect of antihistamine in alleviating common cold symptoms is unclear (10). Usually, it is administered in an oral dose ranging from of 0.5 to $4 \mathrm{mg}$. The average peak plasma concentration following a single oral dose of $12 \mathrm{mg}$ has been reported to be $0.017 \mathrm{mg} / \mathrm{l}$ at 2 hours (11). The chlorpheniramine blood concentration of the present case was $0.43 \mathrm{mg} / \mathrm{l}$, which is more than 20 times greater than the mean peak plasma level measured after a single therapeutic dose. Blood concentrations reported in two overdose fatalities of chlorpheniramine were 1.1 (12) and $2.6 \mathrm{mg} / \mathrm{l}$ (13). An overdose of antihistamines results in anticholinergic toxicity and acute poisoning; the most dangerous adverse event results from its central stimulating effects. Convulsions are sometimes observed as a central stimulating adverse effect of antihistamines especially in children (14). Although there have been few reports of convulsion and antihistamine overdose in adults, we presume that the generalized convulsion in the present case was caused by acute intoxication with chlorpheniramine, on top of abuse of this antitussive. The possibility of compenents other than dihydrocodeine, methylephedrine, or caffeine are causative agents of convulsion could not be denied; the reported cases of convulsion in association with these agents have been noted to occur under unusual circumstances (1517).

In addition to generalized convulsion, the current case presented with mixed acidosis with lactate accumulation. One previous case of acute poisoning of SS-BRON ${ }^{\mathrm{TM}}$ demonstrated symptoms similar to those in our case, i.e., generalized convulsion and metabolic acidosis with lactate accumulation (7). It is difficult to define the causative agents of acidosis among the components of SS-BRON ${ }^{\mathrm{TM}}$. Overdose of any of the ingredients, or a combined effect of these components of SS-BRON ${ }^{\mathrm{TM}}$ seems to be involved in causing metabolic acidosis. It is also proable that generalized convulsion per se worsened acidosis.

In conclusion, it should be noted that OTC antitussive medication is quite easily obtained in considerable amounts and that abuse could result in severe symptoms such as generalized convulsion and acidosis. Recognizing this type of poisoning is important especially in the practice of emergency medicine.

\section{References}

1. Tani N, Kaneko S, Minamikawa S, Miki H, Haga H. A clinical study of SS-BRON solution-W dependency. Arukoru Kenkyuto Yakubutsu Ison 19: 205-210, 1984 (in Japanese, Abstract in English).

2. Fleming PM. Dependence on dextromethorphan hydrobromide. $\mathrm{Br}$
Med J (Clin Res Ed) 293: 597, 1986.

3. Borde M, Nizamie SH. Dependence on a common cough syrup. Lancet 1: 760-761, 1988.

4. Ishigooka J, Yoshida Y, Murasaki M. Abuse of "BRON": a Japanese OTC cough suppressant solution containing methylephedrine, 
codeine, caffeine and chlorpheniramine. Prog Neuropsychopharmacol Biol Psychiatry 15: 513-521, 1991.

5. Miyatake R, Doi T, Date K, Naitoh T, Suwaki H. Clinical study of BRON-L syrup (cough suppressant) abuse. Nihon Arukoru Yakubutsu Igakkai Zasshi 37: 67-74, 2002 (in Japanese, Abstract in English).

6. Sugihara R, Sannomiya K, Ueyama H, Kumamoto T, Tsuda T. Generalized convulsion, hyperhidrosis, and hyperekinesia due to abuse of "BRON GRANULE TM". A case report. Neurol Med (Tokyo) 48: 463-465, 1998 (in Japanese, Abstract in English).

7. Takenouchi M, Uehara J, Kasai H, Yajima T, Mato T. Tonic convulsion and persistent myoclonus in acute intoxication with an over-the-counter antitussive drug: a case report. Journal of Japanese Association for Acute Medicine 16: 633-638, 2005 (in Japanese, Abstract in English).

8. Gutstein H, Young A. Opioid analgesics. In: Goodman \& Gilman's The Pharmacological Basis of Therapeutics. 11th ed. Brunton L, Ed. McGraw-Hill, New York, 2005: 547-590.

9. O'Brien C. Drug addiction and drug abuse. In: Goodman \& Gilman's The Pharmacological Basis of Therapeutics. 11th ed. Brunton L, Ed. McGraw-Hill, New York, 2005: 607-628.

10. Gunn VL, Taha SH, Liebelt EL, Serwint JR. Toxicity of over-the- counter cough and cold medications. Pediatrics 108: E52, 2001.

11. Wogoman H, Steinberg M, Jenkins AJ. Acute intoxication with guaifenesin, diphenhydramine, and chlorpheniramine. Am J Forensic Med Pathol 20: 199-202, 1999.

12. Reed D. A fatal case involving chlorpheniramine. Clin Toxicol 18: 941-943, 1981

13. Levine B, Jones R, Klette K, Smith ML, Kilbane E. An intoxication involving BRON and verapamil. J Anal Toxicol 17: 381-383, 1993.

14. Skidgel R, Erdos E. Histamine, bradykinin, and their antagonists. In: Goodman \& Gilman's The Pharmacological Basis of Therapeutics. 11th ed. Brunton L, Ed. McGraw-Hill, New York, 2005: 629-652.

15. Haller CA, Benowitz NL. Adverse cardiovascular and central nervous system events associated with dietary supplements containing ephedra alkaloids. N Engl J Med 343: 1833-1838, 2000.

16. Zolezzi M, Al Mohaimeed SA. Seizures with intravenous codeine phosphate. Ann Pharmacother 35: 1211-1213, 2001.

17. Kuo SC, Lin YC, Kao SM, Yang YH. Probable codeine phosphate-induced seizures. Ann Pharmacother 38: 1848-1851, 2004.

(C) 2008 The Japanese Society of Internal Medicine http://www.naika.or.jp/imindex.html 